\title{
High blood pressure in school going adolescents: prevalence and risk factors
}

\author{
Patel $\mathbf{U}^{1}$, Patel $\mathrm{NP}^{2}$, Jain $\mathrm{S}^{3}$, Ratre $\mathbf{B K}^{4}$, Shrivastava $\mathrm{S}^{5}$ \\ ${ }^{1}$ Dr Umesh Patel, Associate Professor in Pediatrics, ${ }^{2}$ Dr. Narmada Prasad Patel, Assistant Professor in Medicine, ${ }^{3}$ Dr Sukrati \\ Jain, MBBS (Intern), ${ }^{4}$ Dr. Bhupendra Kumar Ratre, Associate Professor in Medicine, ${ }^{5}$ Dr Sudeepti Shrivastava, MBBS \\ (Intern). All are affiliated with LN Medical College, Bhopal, MP, India
}

Address for Correspondence: Dr. Umesh Patel. drumeshpatel@gmail.com

\begin{abstract}
Background: Childhood and adolescent hypertension and pre-hypertension is important predictor of long term cardiovascular and neurological disorder. Hypertension may begin in adolescence, perhaps even in childhood. The aim of this study was to determine prevalence of high normal and elevated BP among school children and to assess associated risk factors. Materials and Methods: School going children aged between 11 to 18 years, of four schools were selected by purposive sampling method and blood pressure measurements were taken by mercury sphygmomanometer as per recommendation of American heart association. Hypertension is considered when blood pressure is more than $95^{\text {th }}$ percentile and prehypertension when blood pressure is between $90-95^{\text {th }}$ percentile after third reading. Results: Total prevalence of hypertension in our study was $5.36 \%$. Hypertension in males was $5.37 \%$ and in females was $5.36 \%$. Prevalence of pre-hypertension is more than hypertension. Total prevalence of pre-hypertension was $8.74 \%$, in males it was slightly higher (10.35\%) compare to females $(7.14 \%)$. Prevalence of hypertension in obese was $24.07 \%$ against non-obese $5.56 \%(P<0.001)$. Obese female have higher prevalence of hypertension compare to male obese (29.62\% Vs 18.62\%). Conclusion: Prevalence of hypertension was $5.36 \%$ in the study subjects. Childhood obesity and parental hypertension was found to be significant association for childhood hypertension. Follow-up of children throughout school age makes possible taking of preventative measures and promotion of healthy life style.
\end{abstract}

Keywords: hypertension, pre-hypertension, obesity, risk factors

\section{Introduction}

Historically, hypertension in childhood and adolescents was thought to be an uncommon diagnosis, usually related to an underlying condition, most often paranchymal renal diseases. Primary hypertension was felt to be quite rare. However worldwide unhealthy eating habits (Eg- increase salt intake), dyslipidemia and childhood obesity epidemic has had a profound positive impact on the frequency of hypertension [1]. Over the past several decades, childhood and adolescents hypertension has undergone a considerable conceptual change, as hypertension is a predictor of future development of cardiovascular and neurological diseases along with end organ damage in adults [2- 4]. Incidence of cardiovascular disease has increased in developing countries like India during recent urbanization. Several studies have provided ample

Manuscript received: $15^{\text {th }}$ Apr 2014

Reviewed: $26^{\text {th }}$ Apr 2014

Author Corrected; $29^{\text {th }}$ Apr 2014

Accepted for Publication: $15^{\text {th }}$ May 2014 evidence that hypertension in adult has its onset in childhood [5- 7]. Children and adolescents with elevated blood pressure are more likely to become hypertensive adult. This resulted in increased emphasis on screening asymptomatic children. Pediatric pre-hypertension and hypertension has a complex multi factorial etiology including epidemiological variables and other possible secular changes in lifestyle. Out of them obesity, change in dietary habits, decreased physical activity and increasing stress are most important. Estimated prevalence of hypertension in school going children in developed countries are $1-2 \%$, but there is deficiency of data on exact prevalence of childhood hypertension in most of developing countries including India [8-12].

Hypertension often goes under diagnosed in children [1315] because accurate diagnosis requires the use of standardized growth charts specific for age, gender and height with hypertension defined as a systolic and/or diastolic blood pressure $>95^{\text {th }}$ percentile and prehypertension defined as systolic and/or diastolic blood 
pressure $90-95^{\text {th }}$ percentile for age at least three occasions (WHO). Under diagnosis of hypertension may be even more in developing countries like India, where medical care is limited to symptomatic diseased patients only and childhood hypertension have been overlooked in lieu of more urgent diseases like infection and severe malnutrition.

We have conducted this study to determine the prevalence of high blood pressure in school going children between age group of 11-18 years \& to find out association between prevalence of hypertension and its risk factors.

\section{Methods}

\section{(1) Background Information}

The present study was school based cross sectional study. This study was conducted in four schools (two government and two private schools) in Bhopal city. The school was selected by using purposive sampling method keeping in view operational feasibility. Ethical approval regarding the study was obtained from ethical committee of medical college.

Study was conducted between $16^{\text {th }}$ May 2013 to $31^{\text {st }}$ July 2013 (data collection), as in this period their new sessions was started, there is no much study load over students and later data was analyzed.1006 students of 11-18 years of age were selected as subjects after obtaining consent from school administration. At the time of initiating the study each participant was informed about protocol. As far as possible, free time or physical activity periods were used for this study, so that their routine classes were not affected. We had measured the blood pressure, weight, height, waist circumference and BMI, to fulfill the above objectives. Assessment of risk factors was done by questionnaires that were filled by parents. To collect these data many medical equipments like mercury sphygmomanometer with different size cuff, stadiometer, measuring Tape (Transparent \& non-stretchable), stethoscope and weighing machine (Electronic) were used.

\section{(2) Exclusion Criteria's}

The following subjects were excluded from the study having-

(1) Any acute illness (In last 7 days).

(2) Any chronic systemic disease.

(3) On any type of medication.

(4) Advice for bed rest for more than 7 days in last 3 months.
(5) Absent during the time of conduction of the study due to any reason.

(6) Unwilling for study.

(3) Measurement technique The exact age of children were verified from school records. Children were explained about study in their local language (Hindi or English). A semi structured pre-tested questionnaire was administered to each student and asked to get filled by parents at home. Unsatisfactory or incomplete answers were confirmed by telephonic contact or repeating questionnaire.

Questionnaire including information regarding demographic details (name, age, gender, address, religion, parental education, parental occupation), family history of chronic diseases (Hypertension, diabetes mellitus, ischemic heart disease, cerebro-vascular accidents and other chronic illness if any), dietary habits \& pattern of eating (e.g.-eating of junk food, habits of snaking, eating in front TV etc.) and level of physical activity etc. Children those who had positive family history, was reconfirmed telephonically with parents asking about current medications and doctor's visit.

All anthropometric measurements were taken by trained investigator. Height and weight was measured using electronic weighing machine and stadiometer, with sensitivity $0.01 \mathrm{~kg}$ and $0.1 \mathrm{~cm}$ respectively. Zero error was set after every 5 measurements. Height was measured without footwear and taking all standard precautions. Weight was measured without footwear and minimal clothing. BMI was calculated and children was identified as overweight if BMI was be $>85^{\text {th }}$ percentile and obese if BMI was $>95^{\text {th }}$ percentile.

Blood pressure was recorded by mercury sphygmomanometer using standard method. Participants were directed not to take tea or coffee or do vigorous work, during the preceding 30 minutes before the blood pressure measurements were carried out. The participants were allowed to sit for a minimum of ten minutes. For each student, blood pressure was measured twice in same visit with keeping an interval of minimum 30 minutes and mean blood pressure was calculated. The systolic blood pressure was determined by the onset of the "Korotkoff1 " sound and diastolic blood pressure by its disappearance (Korotkoff-5). Children was consider hypertensive if systolic and/or diastolic blood pressure found to be $>95$ th percentile for height for age and sex. If any student was found hypertensive on first visit, two more measurements were taken at end of second and fourth weeks after first visit. Blood pressure measurement was made by same observer.

\section{Results}

1006 students (502 males and 504 females) from two government and two private schools were included in this study.

Table No 1: General Characteristics of participants 
Research Article

\begin{tabular}{|l|l|l|l|}
\hline Character & Boys & Girls & All \\
\hline Number & 502 & 504 & 1006 \\
\hline Age (years) mean (SD) & $13.13(1.73)$ & $13.62(1.71)$ & $13.37(1.73)$ \\
\hline BMI (Kg/M ${ }^{2}$ mean (SD) & $17.53(4.35)$ & $18.81(3.52)$ & $17.69(3.96)$ \\
\hline $\begin{array}{l}\text { Waist Circumference (cm) } \\
\text { mean (SD) }\end{array}$ & $67.01(9.55)$ & $67.59(9.63)$ & $67.3(9.59)$ \\
\hline
\end{tabular}

Of the 1006 adolescents, 502 was male and 504 was females. The mean age of the study group was $13.37+1.73$ years (range: 11 to 16 years). Mean BMI and Waist circumference were $17.69+\ldots 3.96$ and $67.3+\ldots 9.59$ respectively.

Table No 2: Mean blood pressure and prevalence of elevated BP at $1^{\text {st }}, 2^{\text {nd }}$ and $3^{\text {rd }}$ visit (n=1006)

\begin{tabular}{|c|c|c|c|c|c|c|c|}
\hline Gender & Visit & $\mathbf{N}$ & $\begin{array}{ll}\begin{array}{l}\text { Systolic } \\
(\mathrm{mmHg})\end{array} & \text { BP } \\
\text { Mean (SD) } & \\
\end{array}$ & $\begin{array}{ll}\begin{array}{l}\text { Diastolic } \\
(\mathrm{mmHg})\end{array} & \text { BP } \\
\text { Mean (SD) } & \end{array}$ & $\begin{array}{l}\text { Elevated } \\
\text { systolic BP } \\
(\%)\end{array}$ & $\begin{array}{l}\text { Elevated } \\
\text { diastolic } \\
\text { BP }(\%)\end{array}$ & $\begin{array}{l}\text { Elevated BP } \\
(\%)\end{array}$ \\
\hline \multirow[t]{3}{*}{ Boys } & $1^{\mathrm{st}}$ & 502 & $113.17(8.42)$ & $71.67(6.97)$ & $40(7.96)$ & $37(7.37)$ & $77(15.33)$ \\
\hline & $2^{\text {nd }}$ & 77 & $122.46(9.89)$ & $80.77(8.13)$ & $25(4.98)$ & $15(2.98)$ & $40(7.96)$ \\
\hline & $3^{\text {rd }}$ & 40 & $127.4(10.52)$ & $80.85(11.07)$ & $17(3.38)$ & $10(1.99)$ & $27(5.37)$ \\
\hline \multirow[t]{3}{*}{ Girls } & $1^{\mathrm{st}}$ & 504 & $112.71(8.22)$ & $71.05(7.88)$ & $25(4.96)$ & $25(4.96)$ & $50(9.91)$ \\
\hline & $2^{\text {nd }}$ & 50 & $123.56(10.28)$ & $81.52(6.69)$ & $17(3.37)$ & $18(3.57)$ & $35(6.940$ \\
\hline & $3^{\text {rd }}$ & 35 & $124.17(10.14)$ & $82.45(6.86)$ & $12(2.38)$ & $15(2.97)$ & $27(5.32)$ \\
\hline \multirow[t]{3}{*}{ All } & $1^{\text {st }}$ & 1006 & $112.94(8.32)$ & $71.35(7.44)$ & $69(6.85)$ & $58(5.76)$ & $127(12.62)$ \\
\hline & $2^{\text {nd }}$ & 127 & $122.89(10.02)$ & $81.07(7.58)$ & $42(4.17)$ & $33(3.28)$ & $75(7.45)$ \\
\hline & $3^{\text {rd }}$ & 75 & $125.89(10.40)$ & $81.6(9.32)$ & $36(3.57)$ & $25(2.48)$ & $54(5.36)$ \\
\hline
\end{tabular}

Table No 2 shows that sustained hypertension was noticed in 54 (5.36\%) children after third visit. In first visit there was male predominance with $15.33 \%$ compare to $9.91 \%$ in females. There is no sex differentiation in sustained hypertension after $3^{\text {rd }}$ visit (27 Vs 27). But if we see the ratio of systolic and diastolic hypertension, male children having predominantly systolic hypertension $\left(7.96 \%, 4.98 \% \& 3.38 \%\right.$ in $1^{\text {st }}, 2^{\text {nd }} \& 3^{\text {rd }}$ visit respectively) compare to diastolic hypertension $(7.37 \%, 2.98 \% \&$ $1.99 \%$ in $1^{\text {st }}, 2^{\text {nd }} \& 3^{\text {rd }}$ visit). Whereas females children having marginally higher diastolic hypertension. Mean systolic blood pressure in $1^{\text {st }}, 2^{\text {nd }} \& 3^{\text {rd }}$ was $112.94,122.89 \& 125.89 \mathrm{mmHg}$ respectively, whereas mean diastolic pressure was $71.35,81.07 \& 81.60 \mathrm{mmHg}$ respectively. There is no significant difference in mean blood pressure in boys and girls.

Table No 3: Distribution of Hypertension ( $n=1006)$

\begin{tabular}{|c|c|c|c|c|c|c|c|}
\hline \multirow[t]{2}{*}{ Gender } & \multirow[t]{2}{*}{ Visit } & \multicolumn{2}{|c|}{ Systolic BP } & \multicolumn{2}{|c|}{ Diastolic BP } & \multicolumn{2}{|c|}{ Total } \\
\hline & & Number & $\%$ & Number & $\%$ & Number & $\%$ \\
\hline \multirow[t]{3}{*}{ Male } & $1^{\text {st }}$ & 40 & 7.96 & 37 & 7.37 & 77 & 15.34 \\
\hline & $2^{\text {nd }}$ & 25 & 4.98 & 15 & 2.98 & 40 & 7.96 \\
\hline & $3^{\text {rd }}$ & 17 & 3.38 & 10 & 1.99 & 27 & 5.37 \\
\hline \multirow[t]{3}{*}{ Female } & $1^{\text {st }}$ & 25 & 4.96 & 25 & 4.96 & 50 & 9.91 \\
\hline & $2^{\text {nd }}$ & 17 & 3.37 & 18 & 3.57 & 37 & 6.94 \\
\hline & $3^{\text {rd }}$ & 12 & 2.38 & 15 & 2.97 & 27 & 5.35 \\
\hline
\end{tabular}

Table No-3 shows that prevalence of hypertension in male children were 5.37\% after third visit . Systolic hypertension has more prevalence $(3.38 \%)$ than diastolic hypertension $(1.99 \%)$. Prevalence of hypertension in female children were $5.35 \%$, that is almost same as male children, but prevalence of diastolic hypertension is slightly more than systolic hypertension $(2.97 \%$ Vs $2.38 \%)$. 
Table No 4: Distribution of Pre-Hypertension $(n=1006)$

\begin{tabular}{|l|l|l|l|l|l|l|l|}
\hline \multirow{2}{*}{ Gender } & \multirow{2}{*}{ Visit } & \multicolumn{2}{|c|}{ Systolic BP } & \multicolumn{2}{c|}{ Diastolic BP } & \multicolumn{2}{c|}{ Total } \\
\cline { 2 - 8 } & & \multicolumn{1}{|c|}{ Number } & Number & \multicolumn{2}{c|}{$\%$} & Number & $\%$ \\
\hline \multirow{3}{*}{ Male } & $1^{\text {st }}$ & 46 & 9.16 & 41 & 8.16 & 86 & 17.3 \\
\cline { 2 - 8 } & $2^{\text {nd }}$ & 36 & 7.17 & 25 & 4.96 & 61 & 12.10 \\
\cline { 2 - 8 } & $3^{\text {rd }}$ & 29 & 5.77 & 23 & 4.58 & 52 & 10.35 \\
\hline \multirow{3}{*}{ Female } & $1^{\text {st }}$ & 25 & 4.96 & 71 & 14.08 & 96 & 19.04 \\
\cline { 2 - 8 } & $2^{\text {nd }}$ & 16 & 3.17 & 43 & 8.53 & 59 & 11.70 \\
\cline { 2 - 8 } & $3^{\text {st }}$ & 12 & 2.38 & 24 & 4.76 & 36 & 7.14 \\
\hline
\end{tabular}

Table No-4 revels that prevalence of pre-hypertension in male children is $10.35 \%$. This is almost double than the prevalence of hypertension $(5.37 \%)$. Prevalence of pre-hypertension is $7.14 \%$ in female children. Overall prevalence of pre-hypertension was $8.74 \%$. Compare to male children it is much less but like male it is still higher than hypertension.

Table No 5: Prevalence of Obesity in Study population \& Hypertensive Children

\begin{tabular}{|l|l|l|l|l|l|l|}
\hline & \multicolumn{3}{|c|}{ Study Population } & \multicolumn{3}{c|}{ Hypertensive Population } \\
\cline { 2 - 7 } & Total No & Obese & $\%$ & Total No & Obese & $\%$ \\
\hline Overall & 1006 & 56 & 5.56 & 54 & 13 & 24.07 \\
\hline Male & 502 & 24 & 4.78 & 27 & 5 & 18.51 \\
\hline Female & 504 & 32 & 6.3 & 27 & 8 & 29.62 \\
\hline Chi-square value-33.35
\end{tabular}

Table No 5 shows that overall prevalence in study population is $5.56 \%$, which is slightly more in females $(6.3 \%)$ compare to male $(4.78 \%)$. But when we see the prevalence of obesity in hypertensive children it increase significantly. There is $24.07 \%$ hypertensive children are obese. Prevalence of obesity is more common in females with $29.62 \%$ in respect to male where it is $18.51 \%$. Obesity is very important risk factor for childhood hypertension. Chi-square value is 33.55 and $p$-value is $<0.001$, that is statistically highly significant.

Table No 6: Parental Hypertension (Either/both) and Prevalence of Childhood Hypertension

\begin{tabular}{|l|l|l|}
\hline Parents & Hypertensive Children & Normotensive Children \\
\hline Hypertensive & 39 & 413 \\
\hline Non-Hypertensive & 15 & 539 \\
\hline Chi-square value-16.032 p-value- $<0.001$
\end{tabular}

Table No 6 shows there is significant correlation between parental hypertension and prevalence of childhood hypertension. Chi-square value is 16.032 and $p$ value is $<0.001$, that is statistically highly significant.

\section{Discussion}

Hypertension is a potential risk factor for atherosclerosis of coronary, renal and Cerebral blood vessels [6]. It is, therefore, necessary to identify the children with hypertension. Children with BP $>95$ percentile for age, gender and height is consider hypertensive. The prevalence reported in various other studies ranged from 0.41 to $3.6 \%[1,4,7,11,12]$. Obesity, unhealthy salt rich

food and family history of hypertension were found to be important influencing factors in the development of hypertension in the various studies.

Average Body Mass Index (BMI) in our study population is $17.69+3.96 \mathrm{~kg} / \mathrm{M}^{2}$, females having slightly more BMI $\left(18.81+3.52 \mathrm{~kg} / \mathrm{M}^{2}\right)$ than male children $\left(17.53+4.35 \mathrm{~kg} / \mathrm{M}^{2}\right)$.In hypertensive male average BMI is $18.97+5.9 \&$ in females $20.97+$ 5.38. Dermirchi $\mathrm{H}$ et al [16] in their study "Obesity and asymptomatic hypertension among children aged 6-13 years living in Bursa, Turkey" have found that nearly one hundred and twelve children (11.2\%) were obese. Blood pressure and body mass index (BMI) increased with age, with peak prevalence of hypertension at age 12 and of obesity at age 10. Family physicians should consistently perform blood pressure and BMI measurements as a part of well child visits through late childhood.

In view of increase prevalence of hypertension, BMI is not correlating above findings. Previous studies also shows increase prevalence in overweight \& obesity (Most of the studies done either in mega cities or developed 
countries). This lower BMI may be because malnutrition is more prevalent in central India. Because of poor socioeconomic status parents cannot affords high fees of private school and they admit their children in government schools, where there is clustering of under nourished children.

Overall prevalence of hypertension in our study is $5.36 \%$ $(5.37 \%$ in males \& $5.32 \%$ in females). Previous other studies range from 0.41 to $3.6 \%$. Dermirchi $\mathrm{H}$ et al[16] in their study found slightly higher prevalence $(8.5 \%)$. There is markedly lower prevalence $(3.2 \%)$ in the study conducted by Okpere AN et al [17] Male subjects had a higher systolic BP compared to females. The proportional prevalence was higher in the age group 15-17 years (3.9\%); in those in social classes $\mathrm{V}(9.1 \%)$ and with family history of hypertension (3.6\%). It was however significantly higher in the obese subjects.

Our study shows high prevalence rate, this may be because of recent change in life style, dietary change e gjunk food, erratic diet pattern, more stress in life. Second there was no prevalence study in central India till day. In comparison to hypertension, overall prevalence of prehypertension is more in both gender $(7.14 \%$ in females and $10.35 \%$ in males). This is alarming situation, because if an appropriate step has been not taken timely, after few years when these adolescent become adults, most of them will become hypertensive. Hansen ML et al [18] concluded that there is $3.4 \%$ prevalence of prehypertension in the study. Prevalence of hypertension was $3.6 \%$. McNiece KL et al [19] in their study concluded that prevalence of hypertension was $2.6 \%$ that was lower than our study pre-hypertension was $15.71 \%$, that is much higher than our study.

$5.56 \%$ of the asymptomatic hypertensive children were found to be obese as compared to $15.5 \%, 9.9 \%$ and $5.7 \%$ in various studies [20- 22]. Hypertension in obese children may occur due to increased cardiac output, increased blood volume, excessive sodium intake, increased steroid production and alteration in receptors for various pressure substances. An association between family history of hypertension and hypertension in children has also been found by various studies [23, 24]. The hypertension in these asymptomatic children is, usually essential hypertension which is probably aggravated due to obesity and a positive family history. It is therefore recommended that children of hypertensive parents must be screened to detect asymptomatic hypertension [25]. Influencing factors like obesity should be checked and prevented by advising proper diet and regular exercise at home and schools. Parents should also he advised to take these measures.

Various studies also shows that there is positive correlation between socioeconomic status and pediatric hypertension. But in our study this type of correlation is not there. This may be because of high prevalence of malnutrition even in affluent families. Similarly there is there is no influence of parental education on prevalence of childhood hypertension. Result of our study is statistically not significant.

Our study has some limitation. Blood pressure was not re-assessed in children with normal blood pressure at first visit. So there are chances of under estimation of hypertension in study group, in view of masked hypertension. Only few studies have so for assessed prevalence of masked hypertension in children. Masked hypertension could be a precursor of persistent hypertension and is more frequent among overweight children.

\section{Conclusions}

Hypertension and pre-hypertension were frequently undiagnosed in pediatric population. Several lines of evidence suggest that blood pressure in children and adolescents is increasing in parallel with weight. Our study was undertaken to determine the frequency of undiagnosed hypertension in 11- to 18-years-old children. Few important conclusions of this study are given below-

1. Prevalence of hypertension in study population is $5.36 \%$. This is much higher than results of previous studies.

2. Prevalence of diastolic hypertension in females is more than systolic hypertension, so special attention should be given during measurement of blood pressure in female children \& adolescents.

3. Pre-hypertension is more prevalent than hypertension, means there is very high chances that these pre-hypertensive adolescents become hypertensive adults very soon, if appropriate steps have not been taken.

4. Chances of becoming hypertensive or prehypertensive is more in obese children, so these children should be monitored more frequently for early detection of hypertension.

5. Hypertensive parents are known risk factor for symptomatic hypertension in children. So especial camps should be organized, regular measurement of blood pressure should be taken for these children to identify hypertension in early age, so end organ damage can be prevented or minimized.

6. Socioeconomic status and parental education have no effect on pediatric hypertension.

7. Adapting healthy life style with regular physical activity, changing healthy diet, decreasing TV watching, taking good sleep etc. can prevent hypertension.

8. Regular monitoring of blood pressure of children having risk factors is basic steps by which we can detect asymptomatic hypertensive children in very early age. 
Funding: Nil

Conflict of interest: Nil

Permission from IRB: Yes

\section{References}

1. Munter P, He J, Cutler JA, Wildman RP, Whelton BK. Trends in blood pressure among children and adolescents. JAMA. 2004 May;291 (17):2107-13.

2. Kannel WB. Role of blood pressure in cardiovascular diseases - The Framingham study. Angiology. 1975 Jan;26(1):1-14.

3. Drozdz D, Kawecka-Jaszcz K. Cardiovascular changes during chronic hypertensive states. Pediatr Nephrol. 2013 Sep 12.

4. Hemmings S, Conner A, Maffulli N, Morrissey D. Cardiovascular disease risk factors in adolescent British South Asians and whites: a pilot study.Postgrad Med. 2011 Mar;123(2):104-11.

5. Soudarssanane M, Mathanraj S, Sumanth M, Sahai A, Karthigeyan M. Tracking of blood pressure among adolescents and young adults in an urban Slum of Puducherry. Indian J Community Med. 2008;33(2):10712.

6. Reddy KS, Yusuf S. Emerging epidemic of cardiovascular disease in developing countries. Circulation 1998;97:596-601.

7. MB Soudarssanane, S Mathanraj, MM Sumanth, Ajit Sahai, and M Karthigeyan. Tracking of Blood Pressure Among Adolescents and Young Adults in an Urban Slum of Puducherry. Indian J Community Med. 2008 April; 33(2): 107-112.

8. Hansen ML, Gunn PW, Kaelber DC. Underdiagnosis of Hypertension in Children and Adolescents. JAMA 2007 Aug 22;298(8):874-9.

9. Niray Buch, Jagdish P. Goyal, Nagendra Kumar, Indira Parmar, Jaykaran Charan. Prevalence of Hypertension in school going children of Surat City, Western India. J Cardiovas Dis Res.2011 Oct-Dec; 2(4):228-32.

10. D Narayanappa, HS Rajani, KB Mahendrappa and VG Ravikumar.Prevalence of Prehypertension and Hypertension among Urban and Rural School Going Children. Indian Pediatr 2012;49: 755-756.
11. Sharma A, Grover N, Kaushik S, Bharadwaj R, Sankhyan N. Prevalence of hypertension among school children in Shimla. Indian Pediatr. 2010;47:873-6.

12. Gupta R. Trends in hypertension epidemiology in India. Journal of Human Hypertension. 2004;18:73-8.

13. Matthew L. Hansen, Paul W. Gunn David C. Kaelber . Underdiagnosis of Hypertension in Children and Adolescents. JAMA. 2007;298(8):874-879

14. Hansen ML, Gunn PW, Kaelber DC. Underdiagnosis of hypertension in children and adolescents. JAMA. 2007;298(8):874-9.

15. Gunn PW, Hansen ML, Kaelber DC. Underdiagnosis of pediatric hypertension-an example of a new era of clinical research enabled by electronic medical records. AMIA Annu Symp Proc. 2007 Oct 11:966.

16. Demirci H, Nuhoglu C, Ursavas IS, Isildak S, Basaran EO, Kilic MY. Obesity and asymptomatic hypertension among children aged 6-13 years living in Bursa, Turkey. Fam Pract. 2013 Sep 25.

17. Okpere AN, Anochie IC, Eke FU. Pattern of blood pressure and hypertension in adolescents in port harcourt,nigeria. West Afr J Med. 2013;32(2):93-8.

18. Hansen ML, Gunn PW, Kaelber DC. Underdiagnosis of hypertension in children and adolescents. JAMA. 2007 Aug 22;298(8):874-9.

19. McNiece KL, Poffenbarger TS, Turner JL, Franco KD, Sorof JM, Portman RJ. Prevalence of hypertension and pre-hypertension among adolescents. J Pediatr. 2007 Jun;150(6):640-44.

20. Ogden CL, Flegel KM, Carroll MD, Johnson CL. Prevalence and trends in overweight among US children and adolescents, 1999-2000. JAMA. 2002 Oct;288(14):1728-32.

21. M Shashidhar Kotian, Ganesh Kumar S, Suphala S Kotian. Prevalence and Determinants of Overweight and Obesity Among Adolescent School Children of South Karnataka, India Indian J Community Med. 2010 January; 35(1): 176-178.

22. Khadilkar VV, Khadilkar AV. Prevalence of obesity in affluent school boys in Pune. Indian Pediatr. 2004 Aug;41(8):857-8. 
23. Gopinath B, Hardy LL, Baur LA, Teber E, Mitchell P. Influence of parental history of hypertension on screen time and physical activity in young offspring.J Hypertens. 2012 Feb;30(2):336-41.

24. Okoh BAN, Alikor EAD. Childhood hypertension and family history of hypertension in primary school children in Port Harcourt. Niger J Paed 2013; 40 (2): 184 -188
25. Gilles Paradis, Marie Lambert, Jennifer O'Loughlin, Claudette Lavallée,Jacinthe Aubin, Edgard Delvin,Emile Lévy, James A. Hanley. Blood Pressure and Adiposity in Children and Adolescents. Circulation. 2004; 110: 183238 .

\section{How to cite this article?}

Patel U, Patel NP, Jain S, Ratre BK, Shrivastava S. High blood pressure in school going adolescents: prevalence and risk factors. Pediatr Rev: Int J Pediatr Res 2014;1(1):3-9. doi: 10.17511/ijpr.2014.101.02 